\title{
Sistem Kontrol Pendingin Mobil Ramah Lingkungan Berbasis Android
}

\author{
Jamaaluddin Jamaaluddin ${ }^{1, *}$, Dwi Hadidjaja ${ }^{2}$, dan Ahmad Bahruddin ${ }^{3}$ \\ ${ }^{l}$ Program Studi Teknik Elektro, Universitas Muhammadiyah Sidoarjo, \\ J1. Raya Gelam, Candi, Sidoarjo, Jawa Timur, Indonesia \\ e-mail: Jamaaluddin@umsida.ac.id
}

\begin{abstract}
Abstrak - Pada saat ini banyak pendingin ruangan (AC) pada kendaraan mobil tanpa menggunakan sistem kontrol dimana ketika suhu yang di inginkan sudah tercapai maka ON OFF dilakukan secara manual dan penggunakan freon sebagai media pendingin sangat mengganggu lingkungan. Misalnya pada kendaraan mobil dan sistem pendingin ruangannya (AC) menggunakan freon. Freon memiliki nilai global warming potential yang sangat tinggi. Jika terurai ke udara, bahan ini dapat menyebabkan rusaknya struktur lapisan ozon. Salah satu solusi untuk dapat mengontrol suhu ruangan kendaraan dengan menambah sistem pengendali suhu. Salah satu keuntungan dari pengontrol suhu adalah dapat mengatur suhu yang di inginkan secara otomatis dan menggunakan elemen peltier, karena media pendingin tersebut ramah lingkungan di karenakan tanpa menggunakan Freon. Pada sistem kontrol pendingin mobil ramah lingkungan berbasis android ini digunakan Arduino nano, LM35, Peltier, HC-05, dan Smart Phone.
\end{abstract}

Kata kunci: Arduino nano, fan DC, HC-05, LM35, Peltier, dan Smart Phone

\begin{abstract}
At this time a lot of air conditioner (AC) on the vehicle without using a control system where when the desired temperature has been reached then ON/OFF done manually and use freon as cooling medium is very disturbing environment. For example in a car vehicle and air conditioning system (AC) using freon. Freon has a very high global warming potential value. If decomposed into the air, this material can cause damage to the ozone layer structure. One solution to be able to control the temperature of the vehicle room by adding a temperature control system. One of the advantages of the temperature controller is to set the desired temperature automatically and use peltier elements, because the cooling medium is environmentally friendly in because without using Freon. On the control system of environment-friendly car cooling android-based is used Arduino nano, LM35, Peltier, HC-05, and Smart Phone.
\end{abstract}

Keywords: Arduino nano, fan DC; HC-05, LM35; Peltier, and Smart Phone

\section{PENDAHULUAN}

Kebutuhan listrik masyarakat modern saat ini semakin bertambah. Seakan mereka tidak dapat hidup tanpa kehadiran listrik[1][2][3]. Dalam kehidupan sehari hari listrik ini dapat dikendalikan dengan sistem kendali yang tiap saat juga mengalami perkembangan yang cukup pesat. Apalagi dengan hadirnya kemajuan kecerdasan buatan yang semakin menggelora. Kecerdasan buatan ini bila dimasukkan ke dalam sintem kendali menjadi sesuatu yang menakjubkan[4].

Secara umum teknologi masa kini di buat secara otomatis[5]. Mulai dari buka-tutup pagar otomatis, alaram mobil, hingga parkir otomatis. Perkembangan teknologi yang sangat pesat ini membuat manusia berlomba untuk menciptakan peralatan yang dapat memudahkan aktifitas manusia. Salah satunya adalah pengontrol suhu ruangan melalui smartphone android. Kini smartphone android banyak diminati mulai dari kalangan remaja hingga dewasa, karena, mudahnya dalam pengoprasian dan banyaknya aplikasi yang mudah di dapatkan.
Kemudahan teknologi pada smartphone android ini mengundang banyak para pengembang aplikasi android maka smartphone android dapat di manfaatkan untuk membuat aplikasi yang dapat mengontrol suhu ruangan pada mobil. Pada umumnya, sistem pendingin mobil Tanpa ada kontrol dimana ketika suhu yang di inginkan sudah tercapai maka ON OFF dilakukan secara manual, dan sistem pendingin pada mobil menggunakan freon sebagai media pendingin ruangan. Freon merupakan salah satu refrigerant atau pendingin buatan. Teknologi refrigerasi saat ini menggunakan sistem kompresi gas yang menggunakan refrigeran sebagai penukar kalornya. Refrigerant memiliki nilai global warming potential yang sangat tinggi, yaitu lebih dari 500 kali dibandingkan C02. Jika terurai ke udara, bahan ini dapat menyebabkan rusaknya struktur lapisan ozon (O3). Selain global warming potential yang tinggi. Refrigerant juga memiliki Atmospere life time 15, artinya gas refrigerant akan bertahan di atmosfer selama 15 tahun sebelum terurai.

Untuk lebih mengefektifkan sistem pendingin mobil, maka diperlukan suatu alat yang mampu 
mengontrol suhu pada ruangan mobil tanpa menggunakan freon. Keunggulan lain dari sistem pendingin mobil yaitu dapat mengontrol menggunakan smart phone.

\section{A. Tujuan Penelitian}

Adapun tujuan penelitian Sistem kontrol pendingin ramah lingkungan pada mobil berbasis android adalah:

1. Membuat alat pendingin menggunakan elemen peltier yang tidak menggunakan bahan Freon.

Membuat sistem yang dapat menghubungkan kontrol pendingin dan aplikasi di handphone android

\section{LANDASAN TEORI}

Teori-teori terkait penelitian dan perancangan sistem kontrol pendingin mobil ramah lingkungan berbasis android dapat dijelaskan sebagai berikut :

\section{A. Sensor LM 35}

Sensor LM35 adalah komponen elektronika yang dapat berfungsi untuk mengubah besaran suhu menjadi besaran listrik berupa tegangan. Sensor LM35 yang dipakai dalam penelitian ini berupa komponen elektronika-elektronika yang diproduksi oleh National Semiconductor. Keunggulan LM35 adalah dapat memudahan perancangan dan akuratan tinggi jika dibandingkan dengan sensor suhu yang lain, LM35 juga mempunyai keluaran Karakteristik Sensor suhu LM35 sebagai berikut:

Tabel 1. Karakteristik LM 35[6]

\begin{tabular}{|c|c|c|c|c|}
\hline $\begin{array}{c}\text { Vout } / \mathbf{V} \\
\text { (Tanpa } \\
\text { Beban) }\end{array}$ & $\begin{array}{c}\text { Vout } / \mathbf{V} \\
\text { (Dengan } \\
\text { Beban) }\end{array}$ & $\begin{array}{c}\mathbf{I} / \mathbf{A} \\
\text { (Arus) }\end{array}$ & $\begin{array}{c}\mathbf{P} / \mathbf{W} \\
\text { (Daya) }\end{array}$ & $\begin{array}{c}\eta / \% \\
\text { (Efisiensi) }\end{array}$ \\
\hline 12,00 & 11,99 & 5,65 & 67,74 & 99,91 \\
\hline 11,99 & 11,97 & 5,70 & 68,23 & 99,83 \\
\hline 12,01 & 11,98 & 5,68 & 68,05 & 99,75 \\
\hline 12,01 & 11,99 & 5,68 & 68,10 & 99,83 \\
\hline 12,00 & 11,98 & 5,69 & 68,22 & 99,83 \\
\hline
\end{tabular}

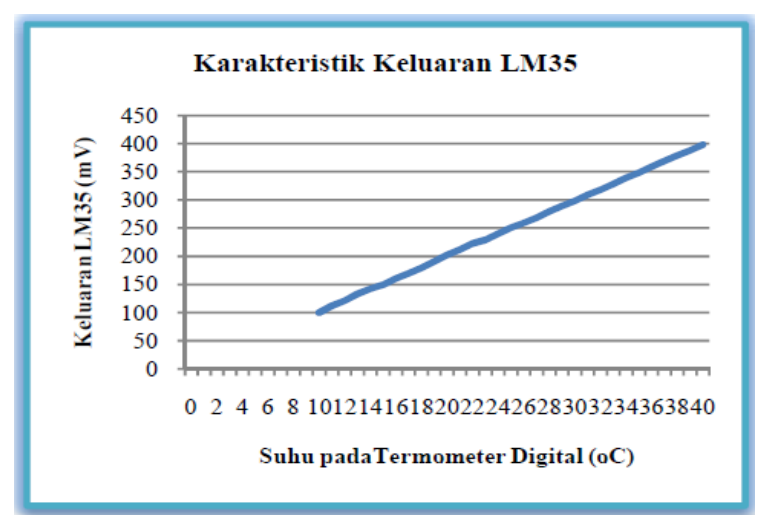

Gambar 1. Karakteristik LM 35[6]

1. Memiliki sensitivitas suhu, dengan faktor linier antara suhu dan tegangan $10 \mathrm{mVolt} /{ }^{\circ} \mathrm{C}$, sehingga dapat dikalibrasi langsung dalam celcius.

2. Memiliki akurasi kalibrasi atau ketepatan yaitu $0,5^{\circ} \mathrm{C}$ pada suhu $25^{\circ} \mathrm{C}$
3. Memiliki jangkauan maksimal suhu antara $-55^{\circ} \mathrm{C}$ sampai dengan $+150^{\circ} \mathrm{C}$.

4. Bekerja pada tegangan 4 sampai dengan 30 volt.

5. Memiliki arus yang rendah yaitu kurang dari $60 \mu \mathrm{A}$.

6. Memiliki pemanasan yang rendah (low-heating) yaitu kurang $0,1^{\circ} \mathrm{C}$ pada saat di udara

7. Memiliki impedansi keluaran rendah yaitu $0,1 \mathrm{~W}$ untuk beban $1 \mathrm{~mA}$.

8. Memiliki ketidaklinieran sekitar $\pm 1 / 4{ }^{\circ} \mathrm{C}$

\section{B. Mikrokontroler Arduino Nano}

Arduino adalah sebuah produk design system minimum mikrokontroler yang di buka secara bebas. arduino menggunakan bahasa pemrograman $\mathrm{C}$ yang telah dimodifikasi dan sudah ditanamkan programmer bootloader yang berfungsi untuk menyembatani antara software compiler arduino dengan mikrokontroler. Untuk koneksi dengan komputer menggunakan RS232 to TTL Converter atau menggunakan Chip USB ke serial converter seperti FTDI FT232. Arduino membuka semua sourcenya mulai dari diagram rangkain, jalur PCB, software compiler, dan bootloadernya.[7]

\section{Relay}

Relay adalah Saklar yang dioperasikan secara listrik dan merupakan komponen Electromechanical (Elektromekanikal) yang terdiri dari 2 bagian utama yaitu Elektromagnet (Coil) dan Mekanikal (seperangkat saklar/switch). Relay menggunakan Prinsip Elektromagnetik untuk dapat menggerakkan Kontak Saklar sehingga dengan arus listrik yang kecil dapat menghantarkan listrik yang bertegangan lebih tinggi. Sebagai contoh, dengan Relay yang menggunakan Elektromagnet 6Volt dan $50 \mathrm{~mA}$ mampu menggerakan Armature Relay (yang berfungsi sebagai saklarnya) untuk menghantarkan listrik sampai dengan 220V 2A.

\section{Module HC 05}

Bluetooth merupakan sebuah teknologi komunikasi wireless yang beroperasi pada pita frekuensi 2,4 - 2,83 $\mathrm{GHz}$ unlicensed ISM (Industrial, Scientific and Medical). Bluetooth mampu menyediakan layanan komunikasi data antara host-host bluetooth dengan jarak jangkauan layanan yang terbatas .[8]

Modul bluetooth seri HC memiliki banyak jenis dan varian, yang secara garis besar terbagi menjadi 2 yaitu jenis industrial series ( $\mathrm{HC}-03, \mathrm{HC}-04$ ) dan civil series ( HC-05, HC-06 ). Modul Bluetooth serial, yang selanjutnya disebut dengan modul BT saja digunakan untuk mengirimkan data serial TTL via bluetooth. Modul BT ini terdiri dari 2 jenis yaitu Master dan Slave.

\section{E. Elemen Peltier}

Thermoelectric generator merupakan teknologi pembangkit listrik menggunakan Energi Panas (kalor). 
Pada umumnya Peltier adalah keramik yang menghasilkan energy panas dan dingin jika di beri tegangan .

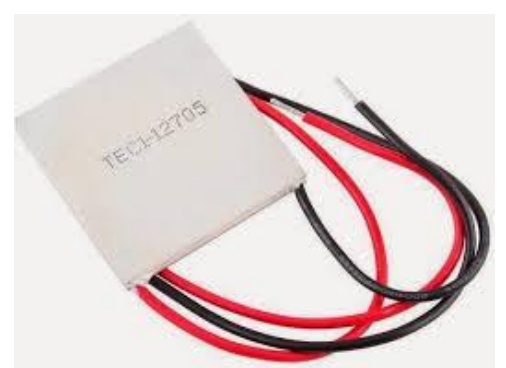

Gambar 2. Bentuk fisik peltier[9]

Namun pada Prinsip Thermoelectrik, Elemen Peltier jika di panaskan salah satu sisinya dan pada sisi lain panasnya dibuang, maka dapat menghasilkan Tegangan. Teknologi termoelektrik bekerja dengan mengonversi energi panas menjadi energi listrik secara langsung. Cara kerja generator menggunakan elemen peltier adalah apabila ada perbedaan suhu $30 \mathrm{c}^{\mathbf{o}}$ ata u lebih diantara kedua sisi peltier maka peltier akan menghasilkan energi listrik. Semisal contoh suhu heatsink yang dipanaskan $85^{\circ} \mathrm{c}$ sedangkan suhu heatsink pembuangan panas $55 \mathrm{c}^{\circ}$ sehingga elemen peltier mengalami selisih perbedaan suhu $30 \mathrm{c}^{\circ}$, semakin Jauh selisih suhunya maka listrik yang di hasilkan akan semakin besar, namun sebaiknya jika terlalu panas bisa Overheat dan menyebabkan rusaknya solderan Pada batangan BIsmuth didalam Peltier.

\section{METODOLOGI PENELITIHAN}

\section{A. Blok Diagram Sistam}

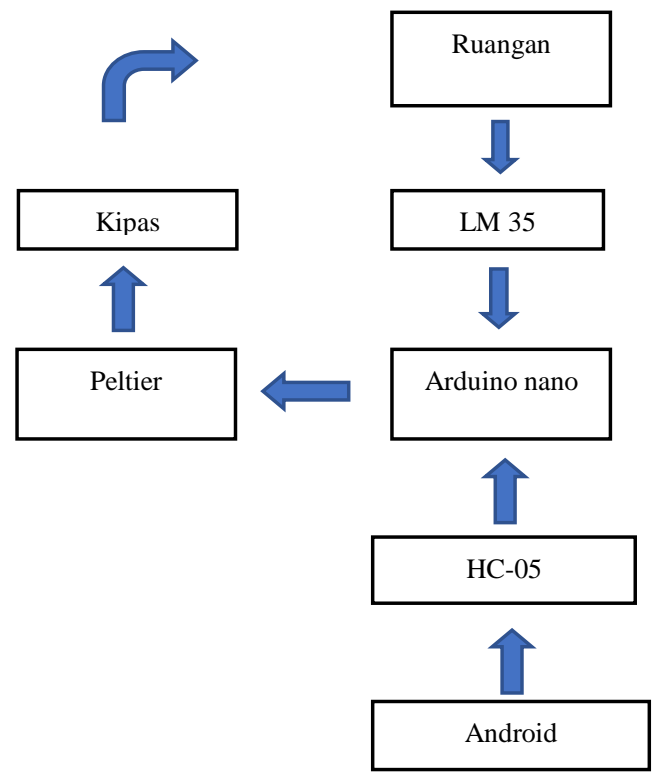

Gambar 3. Blok Diagram Sistem

Pada Gambar 3 merupakan Diagram blok Sistem kontrol / pendingin ruangan mobil yang ramah lingkungan berbasis android. Bagian-baagian blok pada gambar dapat dijelaskan sebagai berikut:

1. Ruangan disini merupakan sebuah objek yang akan di ukur suhunya
2. LM 35 berfungsi sebagai sensor yang mampu mendeteksi suhu ruangan yang kemudian mengirim akan di olah oleh Arduino Nano

3. Arduino Nano adalah sebuah controller untuk mengontrol suatu sistem

4. Module HC-05 berfungsi sebagai protokol sistem yang bertugas mengirim dan menerima data dari Android ke Arduino Nano

5. Android disini akan berfungsi sebagai pengatur suhu yang di inginkan

6. Peltier di sini berperan sebagai alat pendingin untuk mendinginkan ruangan

7. Heatsink berfingsi sebagai penghantar kalor dari ruangan ke peltier

\section{B. Flowchart Aplikasi}

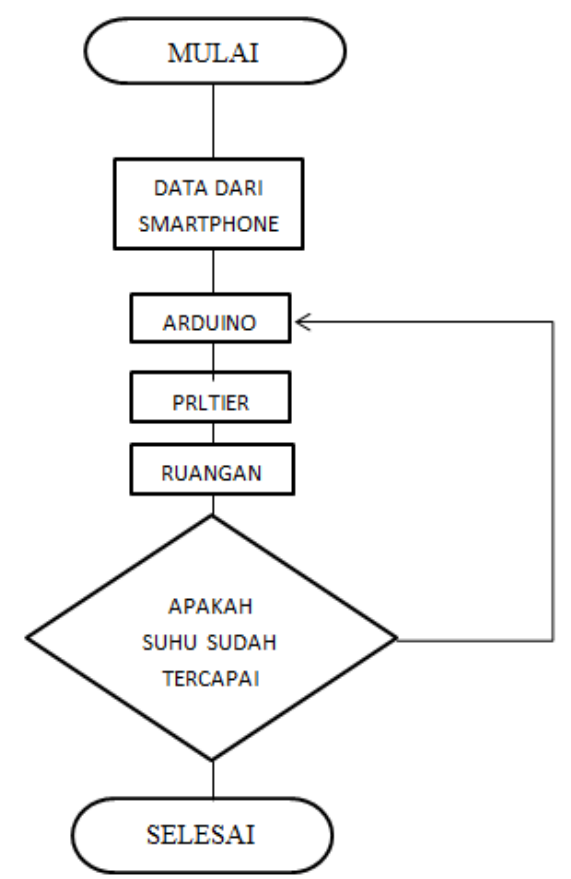

Gambar 4. Flowchart Aplikasi

Pada gambar 4 merupakan flowchart aplikasi dimana pada saat mulai smartphone mengirim suhu revrensi, dan akan diterima oleh arduino. Kemudian arduino akan menghidupkan peltier untuk mendinginkan ruangan. Jika suhu belum tercapai maka akan di kembalikan ke arduino. Jika suhu sudah memenuhi ravrensi maka selesai.

\section{Pembuatan Alat}

Ada beberapa tahab dalam pembuatan sistem pendingin mobil ramah lingkungan berbasis android yaitu pembuatan hardware dan sofware. Berikut tahapan-tahapan pembuatan:

1. Pembuatan Hardwere

Secara umum rangkaian alat ukur ini dapat dilihat pada gambar 5 dimana semua modul terhubung sesuai dengan rangkaian sehingga dapat melakukan pengontrolan dari device android. 


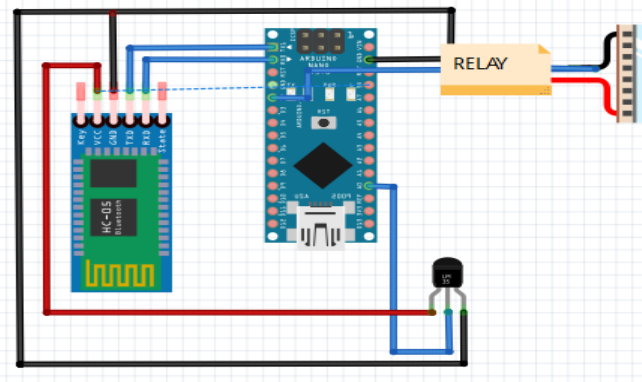

Gambar 5. Skema rangkaian

Pada rangkaian alat ukur ini pin-pin yang digunakan pada modul arduino nano dapat dilihat pada tabel 2 berikut:

Tabel 2. Konfigurasi pin arduino nano

\begin{tabular}{|c|c|}
\hline Pin Arduino & Keterangan \\
\hline A0 (Analog) & Terhubung pin In put LM 35 \\
\hline TXD & Terhubung pin RXD HC-05 \\
\hline RXD & Terhubung pin TXD HC-05 \\
\hline D2 (Digital) & Terhubumh dengan Relay \\
\hline$+5 \mathrm{~V}$ & Vcc \\
\hline Gnd & ground \\
\hline
\end{tabular}

Pada tabel di atas adalah keterangan-keterangan pin yang terhubung pada arduino nano.

\section{Koneksi Sensor LM 35 ke Arduino}

Pada rangkaian kontrol ini, terdapat pin-pin modul arduino nano yang terhubung pada LM 35 dapat dilihat pada gambar 6 berikut:

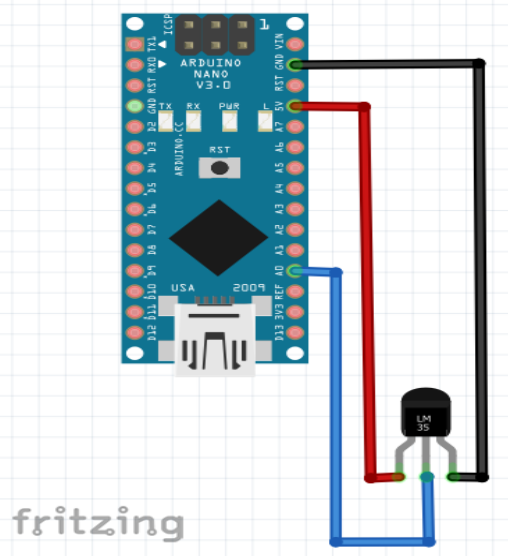

Gambar 6. Skema sensor LM 35 ke Arduino

Tabel 3. Konfigurasi pin LM 35

\begin{tabular}{|c|c|}
\hline Pin Arduino & Keterangan \\
\hline$+5 \mathrm{~V}$ & Terhubung pin Vcc LM 35 \\
\hline Gnd & Terhubung pin ground LM 35 \\
\hline A0 (Analog) & Terhubung pin OUT LM 35 \\
\hline
\end{tabular}

Keterangan tabel di atas adalah pin VCC pada LM35 terhubung dengan $+5 \mathrm{~V}$ pada arduino nano, pin ground LM35 terhubung pada Gnd arduino nano dan pin out LM35 terhubung pada A0.

\section{Koneksi HC-05 ke Arduino}

Pada rangkaian kontrol ini, terdapat pin-pin modul arduino nano yang terhubung pada HC 05 dapat dilihat pada gambar 7 berikut

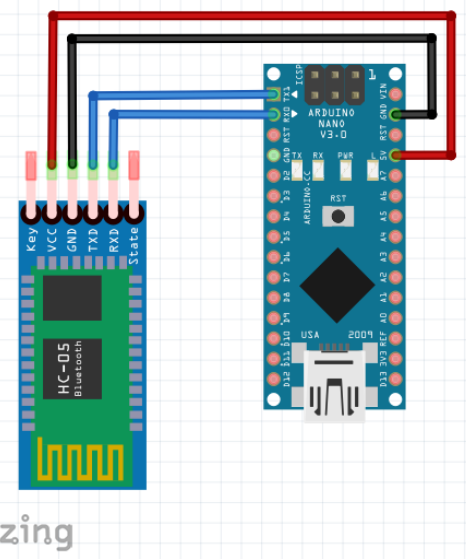

Gambar 7. Skema HC-05 ke Arduino

Tabel 4. Konfigurasi PIN HC 05

\begin{tabular}{|l|l|}
\hline \multicolumn{1}{|c|}{ Pin Arduino } & \multicolumn{1}{c|}{ Keterangan } \\
\hline TXD & Terhubung pin RXD HC-05 \\
\hline RXD & Terhubung pin TXD HC-05 \\
\hline$+5 \mathrm{~V}$ & Terhubung pin Vcc HC-05 \\
\hline Gnd & Terhubung pin ground HC-05 \\
\hline
\end{tabular}

Keterangan tabel di atas adalah pin RXD pada HC-05 terhubung dengan pin TXD pada arduino nano, pin TXD pada HC-05 terhubung dengan pin RXD pada arduino nano, pin Vcc pada $\mathrm{HC}-05$ terhubung dengan pin $+5 \mathrm{~V}$ pada arduino nano dan pin ground pada HC-05 terhubung dengan Gnd pada arduino nano.

4. Koneksi Relay ke Arduino

Pada rangkaian kontrol ini, terdapat pin-pin modul arduino nano yang terhubung pada relay dapat dilihat pada gambar 8 berikut :

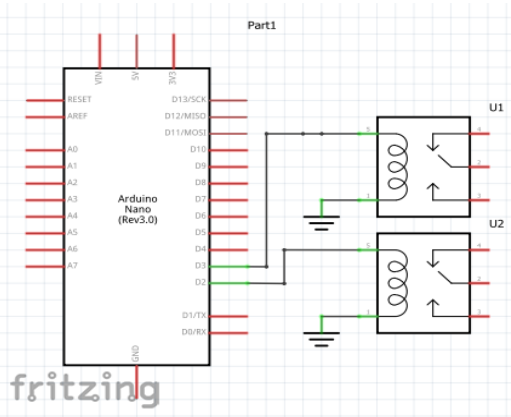

Gambar 8. Skema Relay ke Arduino 
Tabel 5. Konfigurasi PIN Relay

\begin{tabular}{|l|l|}
\hline \multicolumn{1}{|c|}{ Pin Arduino } & \multicolumn{1}{|c|}{ Keterangan } \\
\hline D2 & Terhubung pin Relay 1 \\
\hline D3 & Terhubung pin Relay 2 \\
\hline Gnd & $\begin{array}{l}\text { Terhubung pin ground } \\
\text { Relay1 dan Relay 2 }\end{array}$ \\
\hline
\end{tabular}

Keterangan tabel di atas adalah pin relay 1 terhubung dengan pin D2 pada arduino nano, pin relay 2 terhubung dengan D3 arduino nano dan pin ground relay 1 dan relay 2 terhubung pin Gnd pada arduino nano.

\section{HASIL DAN PEMBAHASAN}

Pengujian dilakukan guna mengetahui cara kerja dari alat ini yang sesuai dengan perencanaan. Selain itu, Pengambilan data pengujian dilakukan dari setiap bagian sistem dan sistem keseluruhan. Adapun pengujian yang dilakukan sebagai berikut:

\section{A. Pengujian Arduino Nano}

Mikrokontroller arduino nano dapat diuji dengan menggunakan program dan rangkaian sederhana. Program dibuat untuk memastikan semua pin pada mikrokontroller masih berfungsi. Program pengujian dilakukan dengan membuat program menyalakan led pada pin 13 arduino nano, saat pengujian arduino nano hanya diprogram untuk menyalakan led, ini bertujuan untuk mengetahui apakah arduino nano masih bekerja dengan baik atau rusak.

Tabel 6. Hasil Percobaan Arduino Nano

\begin{tabular}{|c|c|c|c|c|}
\hline NO & PIN & $\begin{array}{c}\text { INPUT } \\
\text { LOW }\end{array}$ & $\begin{array}{c}\text { INPUT } \\
\text { HIGH }\end{array}$ & Keterangan \\
\hline 1 & 0 & Mati & Hidup & Normal \\
\hline 2 & 1 & Mati & Hidup & Normal \\
\hline 3 & 2 & Mati & Hidup & Normal \\
\hline 4 & 3 & Mati & Hidup & Normal \\
\hline 5 & 4 & Mati & Hidup & Normal \\
\hline 6 & 5 & Mati & Hidup & Normal \\
\hline 7 & 6 & Mati & Hidup & Normal \\
\hline 8 & 7 & Mati & Hidup & Normal \\
\hline 9 & 8 & Mati & Hidup & Normal \\
\hline 10 & 9 & Mati & Hidup & Normal \\
\hline 11 & 10 & Mati & Hidup & Normal \\
\hline 12 & 11 & Mati & Hidup & Normal \\
\hline 13 & 12 & Mati & Hidup & Normal \\
\hline 14 & 13 & Mati & Hidup & Normal \\
\hline
\end{tabular}

Dari pengujian arduino nano yang dilakukan dapat diketahui bahwa arduino nano dalam kondisi baik karena saat dilakukan pengujian, program dicompile ke dalam arduino nano. Pengujian pin digital output di arduino nano yaitu pin 0 sampai pin 13 dapat memberikan respon dengan hasil lampu led yang dipasangkan pada pin 0 sampai pin 13 dapat menyala.

\section{B. Pengujian Peltier}

Untuk menguji peltier yaitu menggunakan tegangan 12 VDC karena spesifikasi peltier yang digunakan memiliki tegangan kerja 12VDC. peltier di dihubungan dengan tegangan 12VDC pada kabel merah di hubungkan ke positif $12 \mathrm{VDC}$ dan kabel hitam di hubungkan ke negative 12VDC. Jika peltier di beri arus 12 VDC dapat memindahkan kalor dari sisi ke sisi lain maka peltier dalam keadaan normal. Jika peltier diberi arus 12 VDC tidak dapat memindahkan kalor dari sisi ke sisi lain maka peltier dalam keadaan rusak.

Tabel 7. Hasil Percobaan peltier

\begin{tabular}{|c|c|c|c|}
\hline No & $\begin{array}{c}\text { Kondisi } \\
\text { (Tegangan } \\
\text { 12VDC) }\end{array}$ & $\begin{array}{c}\text { Output } \\
\text { (Indicator } \\
\text { Lamp) }\end{array}$ & Kesimpulan \\
\hline 1 & 12VDC & $\begin{array}{c}\text { Dapat } \\
\text { memindahkan } \\
\text { kalor }\end{array}$ & Bekerja normal \\
\hline 2 & 0VDC & $\begin{array}{c}\text { Tidak dapat } \\
\text { memindahkan } \\
\text { kalor }\end{array}$ & Bekerja normal \\
\hline
\end{tabular}

Dari pengujian peltier yang dilakukan dapat diketahui bahwa peltier dalam kondisi baik karena saat dilakukan pengujian berjalan normal.

\section{Pengujian $\mathrm{HC} 05$}

Untuk menguji sebuah HC 05 dibutuhkan smartphone dan powersupply karena HC 05 di pergunakan sebagai penghubung smartphone. Dalam pengujian HC 05 akan di beri catudaya sehingga led pada HC 05 menyala. Pada smart phone bluetooth akan di nyalakan dan akan mencari perangkat Bluetooth $\mathrm{HC} 05$ tersebut. Jika HC 05 dalam keadaan normal maka perangkat bluetooth pada smart phone dapat menemukan perangkat $\mathrm{HC}$ 05. Jika perangkat bluetooth pada smart phone tidak dapat menemukan perangkat HC 05 maka, HC 05 dalam keadaan rusak.

Tabel 8. Pengujian Jarak HC 05

\begin{tabular}{|c|c|c|}
\hline NO & Jarak(meter) & Koneksi \\
\hline 1 & 1 & Terhubung \\
\hline 2 & 2 & Terhubung \\
\hline 3 & 3 & Terhubung \\
\hline 4 & 4 & Terhubung \\
\hline 5 & 5 & Terhubung \\
\hline 6 & 6 & Terhubung \\
\hline 7 & 7 & Terhubung \\
\hline 8 & 8 & Terhubung \\
\hline 9 & 9 & Terhubung \\
\hline 10 & 10 & Terhubung \\
\hline 11 & 11 & Terhubung \\
\hline 12 & 12 & Terhubung \\
\hline 13 & 13 & Terhubung \\
\hline 14 & 14 & Terhubung \\
\hline 15 & 15 & Tidak terhubung \\
\hline 16 & 16 & Tidak terhubung \\
\hline 17 & 17 & Tidak terhubung \\
\hline
\end{tabular}

Dari hasil pengujian HC 05 dapat terhubung dengan smartphone dengan jarak maksimal 14 meter dan tidak dapat terkoneksi pada jarak 15 meter. 


\section{Pengujian LM 35}

Untuk menguji LM35 sebagai sensor suhu pada miniatur mobil diperlukan ketelitian pemasangan output pada LM 35 yang akan dihubungkan dengan port pada arduino nano. Untuk pregujian ini di gunakan port A0 pada arduino nano. Karena arduino nano digunakan untuk mengolah data yang di dapat oleh sensor LM 35 .

Tabel 9. Pengujian LM 35

\begin{tabular}{|c|c|c|}
\hline NO & $\begin{array}{c}\text { LM 35 } \\
\text { (Tegangan } \mathrm{mV})\end{array}$ & $\begin{array}{c}\text { Thermometer } \\
\text { Digital }\left(\mathbf{C}^{\mathbf{o}}\right)\end{array}$ \\
\hline 1 & 317 & 29,5 \\
\hline 2 & 318 & 30,5 \\
\hline 3 & 319 & 31,0 \\
\hline 4 & 325 & 31,5 \\
\hline 5 & 328 & 31,9 \\
\hline 6 & 339 & 32,4 \\
\hline 7 & 340 & 32,9 \\
\hline 8 & 353 & 34,4 \\
\hline 9 & 367 & 35,9 \\
\hline 10 & 380 & 36,3 \\
\hline
\end{tabular}

\section{E. Pengujian Keseluruhan}

Pada pengujian alat ini ada langkah-langkah pengujian yang di lakukan yaitu sebagai berikut :

1. Beri catu daya pada sistem kontrol pendingin

2. Satukan Lm 35 dengan sensor thermometer digital kemudian tempelkan pada bagian dingin heatsink dengan dimensi $7 \times 7 \times 3 \mathrm{~cm}$ yang berada dalam ruangan $22885 \mathrm{~cm}^{3}$

3. Aktifkan Bluetooth pada smartphone

4. Buka aplikasi pada smartphone yang sudah terinstal aplikasi sistem kontrol pendingin

5. Pilihan "SUHU' pada screen 1 untuk melihat suhu pada miniatur mobil

6. Tekan gambar berlogo Bluetooth untuk Mengkoneksikan smart phone pada HC 05, jika sudah terkoneksi maka akan terlihat suhu pada screen 2

7. Pilih 'KONTROL SUHU', untuk mengontrol suhu pada screen 1

8. Tekan Gambar berlogo Bluetooth untuk mengkoneksikan smartphone dengan HC 05, jika sudah terkoneksi maka pilih salah satu dari suhu refrensi.

\section{F. Hasil Pescobaan}

Dari hasil percobaan dengan suhu awal $40^{\circ} \mathrm{c}$ menggunakan elemen peltier. Pada miniatur mobil. Hasil Percobaan

\begin{tabular}{|l|r|r|r|r|r|r|}
\hline \multirow{2}{*}{ waktu } & \multicolumn{7}{|c|}{ PENGUJIAN KE- } \\
\cline { 2 - 8 } & \multicolumn{2}{|c|}{1} & \multicolumn{2}{|c|}{2} & \multicolumn{2}{l|}{3} \\
\hline & LM35 & Thermom & LM35 & Thermom & LM35 & Thermom \\
\hline 1 Menit & 33.6 & 33.8 & 33.8 & 33.9 & 33.7 & 33.8 \\
\hline 5 Menit & 29.5 & 29.2 & 29.8 & 29.6 & 29.7 & 29.6 \\
\hline 7 Menit & 28.4 & 28.9 & 28.7 & 28.4 & 28.6 & 28.8 \\
\hline 10 Menit & 28.3 & 28.6 & 28.5 & 28.9 & 28.5 & 28.7 \\
\hline 15 Menit & 27.9 & 28 & 28.1 & 28.3 & 28 & 28.3 \\
\hline
\end{tabular}

\begin{tabular}{|r|r|r|r|r|r|}
\hline \multicolumn{2}{|c|}{ rata-rata } & \multicolumn{2}{c|}{ standart deviasi } & & \\
\cline { 1 - 4 } LM35 & Thermom & & \\
\hline 33.70 & 33.83 & 0.10 & 0.06 & 0.13 & $99.6 \%$ \\
\hline 29.67 & 29.47 & 0.15 & 0.23 & 0.20 & $99.3 \%$ \\
\hline 28.57 & 28.70 & 0.15 & 0.26 & 0.13 & $99.5 \%$ \\
\hline 28.43 & 28.73 & 0.12 & 0.15 & 0.30 & $99.0 \%$ \\
\hline 28.00 & 28.20 & 0.10 & 0.17 & 0.20 & $99.3 \%$ \\
\hline
\end{tabular}

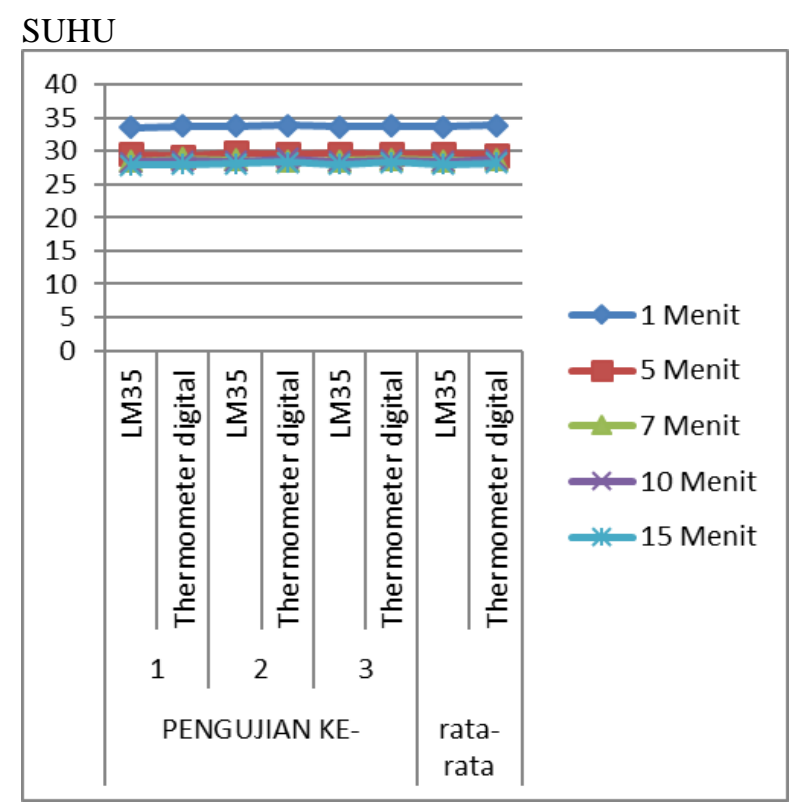

Ketepatan $=p=1-\left[\frac{Y n-X n}{X n} \mid \times 100 \%\right.$

Standar deviasi $(s)=\sqrt{\frac{\sum(X i-X) 2}{n-1}}$

Dimana : $\quad X=$ Rata-rata

$\mathrm{Xi}=$ Data ke-i

$\mathrm{n}=$ Banyak data

YN = PENGUKURAN ALAT

\section{KESIMPULAN}

Pada bab ini akan diuraikan kesimpulan yang dapat diambil dari pembahasan sebelumnya dan saran mengenai masalah yang bisa dibahas sebagai kelanjutan dari penelitian ini. 


\section{A. Kesimpulan}

Setelah dilakukan pengujian Sistem kontrol pendingin mobil ramah lingkungan berbasis android dapat ditarik kesimpulan sebagai berikut:

1. Sistem pendingin menggunakan peltier, dapat Mendinginkan ruangan pada mobil tanpa mengeluarkan freon dimana zat ini dapat merusak lapisan ozon.

2. Sistem kontrol pada arduino dapat mengatur suhu jika suhu refrensi dari smartphone sudah di capai maka arduino akan memutus arus pada elemen peltier.

3. Aplikasi yang dibuat melalui app inventor dan di install di smartphone android mampu menghubngkan dari smartphone ke arduino melalui bluetooth HC-05 dan berhasil menurunkan suhu dengan cara mengontrol relay sehingga elemen peltier dapat memindahkan kalor dari dalam ruang pada mobil ke luar ruangan pada mobil.

\section{B. Saran}

Dengan hasil yang dicapai diharapkan dapat dikembangkan untuk alat pendingin ramah lingkungan supaya dapat mengurangi dampak dari pemanasan global. Semoga skripsi ini dapat disempurnakan lebih baik agar bermanfaat bagi masyarakat luas.

\section{REFERENSI}

[1] A. G. Jamaaluddin, J., Hadidjaja, D., Sulistiyowati, I., (...), Syahrorini, S., Abdullah, "Very Sort Term Load Forecasting Using Interval Type - 2 Fuzzy Inference System (IT- 2 FIS) (Case Study: Java Bali Electrical System)," in IOP Conference Series: Materials Science and Engineering, 2018.J. Clerk Maxwell, A Treatise on Electricity and Magnetism, $3^{\text {rd }}$ ed., vol. 2. Oxford: Clarendon, 1892, pp.68-73.

[2] J. Jamaaluddin, D. Hadidjaja, I. Sulistiyowati, E. A. Suprayitno, I. Anshory, and S. Syahrorini, "Very short term load forecasting peak load time using fuzzy logic," in IOP Conference Series: Materials Science and Engineering, 2018.

[3] Jamaaluddin;Imam Robandi, "Short Term Load Forecasting of Eid Al Fitr Holiday By Using Interval Type - 2 Fuzzy Inference System ( Case Study: Electrical System of Java Bali in Indonesia )," in 2016 IEEE Region 10, TENSYMP, 2016, vol. 0, no. x, pp. 237-242.

[4] Jamaaluddin and Sumarno, "Planning integrated electric power grounding systems in buildings (Perencanaan sistem pentanahan tenaga listrik terintegrasi pada bangunan)," Jeee-U(Journal Electr. Electron. Eng., vol. 1, no. 1, pp. 29-33, 2017.

[5] P. S. T. E. U. M. S. Imron Muhammad Ali, Jamaaluddin, "Rancang Bangun Sistem Informasi Parkir Mobil Otomatis Pada Gedung Bertingkat Berbasis Arduino Mega 2560," TRIACS, vol. 2, no. 4, pp. 9-14, 2017.

[6] R. Umboh, J. O. Wuwung, E. K. Allo, and B. S. Narasiang, "Perancangan Alat Pendinginan Portable Menggunakan Elemen Peltier," Tek. Elektro dan Komput., vol. 1, pp. 1-6, 2012.

[7] V. Masinambow, "Pengendali Saklar Listrik Melalui Ponsel Pintar Android," pp. 1-9, 2014.

[8] A. F. Silvia, E. Haritman, and Y. Muladi, "Rancang Bangun Akses Kontrol Pintu Gerbang Berbasis Arduino Dan Android," Electrans 2014, vol. 13, no. 1, pp. 1-10, 2014.

[9] F. Gandi and M. Yusfi, "Berbasis Mikrokontroler ATmega8535," J. Fis. Unand, vol. 5, no. 1, pp. 35-41, 2016. 